\title{
Experience of Enhancing Cross-Border Collaboration in professional training of industry personnel
}

\author{
Oksana Filatova 1,2,*, Maksim Gordeev², Larisa Gorbunova ${ }^{3}$, Irina Nagaeva ${ }^{4}$, Olga \\ Mishunenkova ${ }^{5}$ \\ ${ }^{1}$ National Research Nuclear University MEPhI Obninsk Institute for Nuclear Power \\ Engineering,Studgorodok str., 1, Obninsk, Kaluga region,249040, Obninsk, Russian Federation \\ ${ }^{2}$ Rosatom Technical Academy, Kurchatov str., 21, Obninsk, Kaluga region, 249031, Russian \\ Federation \\ ${ }^{3}$ Moscow Institute of Economics, Artyukhina str., 6/1, Moscow, 107140, Russian Federation \\ ${ }^{4}$ Moscow International University, Leningradsky Prospect, 17, Moscow, 125040, Russian \\ Federation \\ ${ }^{5}$ Lomonosov Moscow State University,GSP-1,Leninskie Gory, Moscow, 119991, Russian \\ Federation
}

\begin{abstract}
The article considers the problem of the fourth industrial revolution influence on changing the forms and educational technologies of personnel professional training of industry personnel and justifies the importance of cooperation between educational organizations of different countries in coordinating professional training programs. The authors explain the importance of harmonization and coordination processes of the Bologna project by the factors of the objective pattern of changing the technological paradigm and the formation of technoscience, diversifying educational technologies, which is actualized by the growing need for new generation specialists. The article emphasizes the importance of international cooperation and international interdisciplinary interaction in the development of forms and technologies of professional training in the logic (The Project of the Digital Competition of EU). On the example of educational projects of Russia and China in nuclear energy, the authors show the mutual influence of factors for the development of professional education in different countries. The article analyzes promising areas of professional training, based on the experience of mutual cooperation and the practice of diversifying programs in Russia and China, including the development of nuclear medicine, wind energy, ASU SMART- cities, the creation of digital products and environmental projects. The methodology of the article is based on research in the field of professional education in the context of informatization and the strategy of digitalization of production technologies, noting the special importance of engineering training in China.
\end{abstract}

\footnotetext{
${ }^{*}$ Corresponding author: OLFilatova@rosatomtech.ru
} 


\section{Introduction}

The dynamic pace of the digital transformation of the economy at the stage of the sixth long wave and the change of the technological paradigm revealed the phenomenon of technoscience, the essential features of which are manifested in the integration and convergence of technologies and the complexity of multidimensional self-developing systems. The formation of a new technological structure outlined the problem of changing the organization of professional training of the corps of engineers, economists, technical specialists for high-tech industries. The human resources potential of international cooperation and integration in the interdisciplinary international interaction of mastering new forms and technologies of professional training and personnel development is of particular importance in the development of energy technologies. The search for educational technologies is unfolding, on the one hand, against the background of the processes of diversification of professional training programs, on the other hand, in the objective need to harmonize the requirements for professional education of specialists, which is also understood in Russia and abroad.

The guidelines for the harmonization of higher education systems in Europe, which Russia joined in 2003 to, were formulated by the Bologna project, in the focus of which a general conceptual field of non-linear dependencies of education on cultural, social and economic factors was formed. The basic principles of the Magna Charta Universitarum proclaimed the right of universities to autonomy, attention to research practice, guarantees of freedom of education and research, and intercommunication of cultures. Achievements of Bologna Process are obvious from different sides, in establishment of close ties between higher education institutions, in the statement of a paradigm of "education through the life", the international openness of the European education, intercountry mobility of students.

Leading universities of Russia, MVTU named after N.E. Bauman, NRNU"MEPhI," Moscow International University, Moscow State University named after M.V. Lomonosov, expand the areas of interaction and cooperation in the implementation of educational projects in international markets. The guidelines for the harmonization of higher education systems in Europe, which Russia joined in 2003 to, were formulated by the Bologna project, in the focus of which a general conceptual field of non-linear dependencies of education on cultural, social and economic factors was formed. The basic principles of the Magna Charta Universitarum proclaimed the right of universities to autonomy, attention to research practice, guarantees of freedom of education and research, and intercommunication of cultures. Achievements of Bologna Process are obvious from different sides, in establishment of close ties between higher education institutions, in the statement of a paradigm of "education through the life", the international openness of the European education, intercountry mobility of students.

Leading universities of Russia, MVTU named after N.E. Bauman, NRNU "MEPhI," Moscow International University, Moscow State University named after M.V. Lomonosov, expand the areas of interaction and cooperation in the implementation of educational projects in international markets. A striking example, the coordination of training programs for engineering and technical personnel, the development of their qualifications, as well as the creation of training centers, the training of foreign students in higher educational institutions of the nuclear energy profile to obtain appropriate qualifications and postgraduate education for subsequent work at nuclear power plants in China.

\section{Materials \& Discussion}


Developing the ideas of the Bologna project, Russia and China are working on the development and implementation of joint programs, the development of academic mobility, as well as on the scientific, technological and innovative direction of cooperation. Participants of the Project 5-100 were People's Friendship University of Russia, SPbPU, FEFU, TSU and other universities. From the Chinese side about 600 educational institutions, including Peking polytechnic University, Tsinghua University, South Chinese technological university, Northeast pedagogical university, Tszyansussky pedagogical university, etc. More than 900 direct agreements have been concluded, specialized associations of Russian and Chinese universities have been created [1].

Since the accession of Russia to the Bologna Declaration, a discussion has unfolded in the scientific and pedagogical community about the advantages, shortcomings, principles and prospects for achieving the goals of the Bologna project. The periodical "Higher Education in Russia" identifies three points of view: an exaggerated assessment of overstated expectations from the heyday of higher education; the expressed fear of Bologna values; a pragmatic position that prevailed, recognizing the fact that "closer integration of the educational systems of the Russian Federation and Europe will strengthen the effect of" mutual pollination... "in the search for higher education of the future" [2]. A number of experts believe that "the Bologna process today does not take root in Russia," due to the differences in the European system of requirements for students, and, as a result, the need for a complete change in the fundamentals of the system "[3].

Scientists of the Kazan (Volga) Federal University sharpen a negative assessment of the Bologna transformations: "Based on an analysis of the structure of the Bologna process, one can conclude that the system is incapacitated in practice in countries outside the European Union" [4]. Meanwhile, the dynamics of the internationalization of Russian higher education is obvious, although it should be recognized that the target of "ensuring the presence of the Russian Federation among the ten leading countries in the world in terms of research and development, including through the creation of an effective higher education system," the goal remains significant until 2030 [5].

Among the positive changes of higher education in the Russian Federation it should be noticed the transition to a two-level European system of education, student mobility, new approaches to assessing qualifications, guidelines for digital maturity of professional competence, the use of digital high technologies in higher education in all possible areas and forms. International cooperation and the inclusion of Russian universities in European scientific and educational projects contributed to the development of professional education, stimulated the democratization of management, initiative and the development of innovative educational technologies.

According to 2019 data, over 7 years, the number of Chinese students in Russian universities has increased almost 2 times, amounting to 30 thousand people. Educational institutions in which citizens of the PRC study are located in 85 cities of Russia, although preference is given to Moscow, St. Petersburg and Far Eastern universities and full-time education. Russia seeks to ensure the global competitiveness of Russian education by implementing the strategic objectives of the national project "Education," as well as the Project 5-100 and improving the international competitiveness of Russian higher education. The main specialties are of the social and humanitarian field, the Russian language, linguistics and literary studies, economics and management, a number of engineering and technical specialties, mechanical engineering, energy, the demand for which has grown in recent years.

NRNU "MEPhI" has developed a number of English-language programs and more than 20 unique copyright training courses, including for the Institute of Intelligent Cybernetic Systems, the bachelor's program of Protected Computational Systems \& Software Development in the field of computer science and computing. Cooperation and 
the development of scientific and educational cooperation between NRNU "MEPhI" and Tsinghua University, one of the best universities in China, can be evaluated productively. The university takes 17th place in the ranking of the best educational institutions in the QS World University Rankings 2019, as well as 10th place in the QS World University Rankings by Subject 2018 in the discipline of "engineering and technology" [6].

Foreign students received the opportunity of practical training at the Resource Center of the NRNU "MEPhI" in the city of Donbass. The decision to create the Resource Center (RC) of NRNU "MEPhI" on the basis of the Donbass Engineering and Technical Institute of NRNU "MEPhI" was made for practical-oriented training of foreign students in the conditions of knowledge-intensive and high-tech production of the nuclear industry. With the support of ROSATOM State Corporation in Donbass, hundreds of foreign students from Moscow and Obninsk have already been able to improve their practical skills [7].

The digital transformation of the economy and social sphere in Russia has objectified the pattern of professional training diversification. Professional training of engineers for enterprises of the energy complex in Russia is carried out in various areas, automation of technological processes, IT systems, 3-D printing, big data, cybersecurity of the nuclear industry, reengineering, additive technologies, design modeling. This approach attracted the attention of Chinese specialists to the Russian experience, although in general in engineering education Chinese universities are oriented towards Western standards.

Nuclear power is a priority in China's economy. According to statistics, at the beginning of 2020, 48 power reactors operate in China, 10 more are being built, and the share of nuclear energy in the total energy balance is $4.2 \%$ [8]. The diversification of nuclear power is also evident in China. Nuclear medicine is actively developing. The publication has formulated the foundations of the system of supervision over nuclear safety of the PRC. Environmental projects are widely welcomed. At the same time, technological innovations are associated with optimizing the professional training of Chinese specialists. Premier of the State Council of China Wen Jiabao, has stressed that the "Rise of China" is ensured through the training of specialists and the development of education.

The scientific press emphasizes that for the industrialization of China, an acute problem is the training of engineering personnel, which is being reformed in the logic of European standards. «Then, engineering education is facing a great challenge» [9]. China has outlined an initiative 'New Engineering Education' (NEE) to reform its engineering education at university level. Despite the China's intention to keep such unique features of its own, «in terms of engineering education, China does value international standards (represented by Western standards) » [10]. China follows the education system of Western standards in engineering education. «It should update its engineering curricula and pedagogy from theoretical knowledge to practice-oriented and outcome based... The engineering concepts, building innovations, and development outlines are weak [11]. A transition from a model centered upon teaching to a model centered upon student learning, allowing students to become aware of knowledge, procedures and values for problem-solving through metacognitive capacities that permit them to reflect consciously on, plan, supervise, regulate and evaluate strategies involved in learning [12].

\section{Results}

The system of professional education for the nuclear industry in Russia is built according to three vectors: management, expert and project. The management vector is the development of managers capable of fulfilling the strategic goals of Rosatom; the expert and project vectors are the improvement of employees' professional skills in the field of their specialization or in the field of special interests of the State Corporation. The project of diversification of professional training programs in the system of retraining and advanced 
training of personnel of the Rosatom Technical Academy includes this complex of organizational and pedagogical means and methods of updating digital resources in the educational process, value and sense tuning of information perception, development of critical thinking and communication skills.

The outline of the professional training diversification project defines significant reversal points for the development of multi-module programs:

- development of individual professional trajectories - readiness for self-education throughout life;

- importance of productive activity in realities of the digital environment, development of "useful knowledge";

- creative thinking and high adaptation of behavior in self-developing structures with mastery of remote access practices;

- priority of social qualities, values, beliefs, emotional intelligence in the cross-cultural space of the digital environment;

- technological competence and professional excellence in non-linear and flexible production technologies to prevent "half-life of competence";

- communicative competence of intercultural interaction.

In the logic of Bologna materials, the requirements of employers and standards of professional qualifications in the development of a single educational space issued a request for an understanding of digital competencies. Russian universities in the development of competencies correlate educational programs with a list of 21 competencies that the European Commission determined for Europe citizens, suggested The Joint Research Centre (JRC) the Digital Competition Framework 2.0 [13]. Such "general competences" are an influence on the development of such skills as: analytical thinking (GC-1), communication skills and writing skills (GC-2), and organizational skills (GC-3) in practice in Russia. The requirements for the results of the implementation of the GEF $3++$ Educational Program have included them in the form: universal, professional and professional. However, digital competencies, like cross-cutting universality for all types of activities, have not become apparent, as in the practice of the EU countries.

In 2019 a training program for 33 specialists of the Tianwan NPP was opened on the basis of the Rosatom Technical Academy, in Obninsk (Kaluga Region). The operator was the Jiangsu Nuclear Power Corporation, JNPC (China). The project for training Chinese nuclear energy specialists along with the Rosatom Technical Academy was developed by Rosenergoatom Concern and Rusatom Service JSC. The program provided for three main stages: theoretical classes at the Obninsk site, practice at the training center in the branches of St. Petersburg and Sosnovy Bor, practical classes at the Leningrad NPP. The main participants in the design and construction of nuclear power plants with VVER-1200 for the People's Republic of China are concentrated in the North-West region.

The results of the training program were presented by the formed competencies of specialists at a practical exam with a demonstration of the basic competencies for the operation of a power unit with a VVER-1200 reactor, legal aspects in the field of peaceful use of nuclear energy.

Chinese participants in training programs note: "To improve technical competencies, we need to cooperate more deeply, openly and mutually beneficial with Russia... we were able to better understand the culture of the Russian people and improve the Russian language. " The importance of cross-cultural factor and bilingual training is also indicated by Russian specialists working on projects in China. Experienced specialists with education in the field of economics, technology, business speak Chinese.

The communicative aspect received special attention in professional training in Russia. Syuy Syutszyuan, Senior Lecturer of Jilin Huaqiao Foreign Languages Institute, 
Changchun, China, comments, «Teaching a foreign language plays the decisive role in teaching any discipline in China. That is why researchers and specialists keep discussing foreign language teaching methods mostly suitable for China. Learning Russian is an inseparable part of foreign language study in China. There are many methods of its teaching: from the audio-visual method and the initial translation method up to the method of conscious comparison and the cognitive method". Teachers of "MEPhI", the basic educational institution of higher professional education in nuclear energy, pay special attention to phonetic exercises (Ushakova Yu.Yu.). Language Teachers of the Faculty of Economics of Lomonosov Moscow State University analyze the possibility of Program Product "My English Lab" use (Mishunenkova O.V.).

The signing of the strategic package of documents determines the main directions for the development of cooperation between Russia and China in the field of nuclear energy for the coming decades, and also allows us to see the prospects for the exchange of vocational education programs.

\section{Conclusion}

The development of professional training programs for nuclear energy and alternative directions of nuclear development within the framework of Russian-Chinese cooperation reflect the objective nature of the principles of the Bologna process in the development of the ideas for broad cooperation between universities, student mobility, research and development. The logic of the development of the Bologna process does not provide for the simultaneous and straightforward achievement of the goals of harmonization of education. The practice of cooperation between universities, including in the nuclear power industry, shows the mutual intellectual enrichment of program participants, cross-cultural understanding, and the formation of a single conceptual space for education.

Among the most notable areas useful, both for Russia and China, it should be noted:

- "Smart City" project - coordination of innovations and advanced technologies of Rosatom organizations for effective urban management, improving the quality of citizens life, creating a comfortable and safe urban environment, modernizing the infrastructure of life support for cities: heat, electricity, water supply based on modern engineering and digital solutions; (by 2021 city Obninsk will be in the project pool);

- "Rosatom School" project - achieving a "supernew" goal by 2025: the formation of an innovative highly effective cluster in the field of general and additional quality education (city Obninsk has entered the pool of project participants);

- projects for the development of the Arctic and its resource development, environmental safety, study and preservation of unique natural ecosystems within the framework of the national project "Ecology";

- development of equipment and radionuclide products production for nuclear medicine and medical radiology, as well as industrial equipment based on radiation technologies (development and creation of commercial processing centers for products based on gammaray installations and electron accelerators); the construction of nuclear medicine centers, including Obninsk zone;

- development of PAN precursor and carbon fiber technologies; advantages of carbon composites - lightness, strength, high performance. It shows one of the highest growth rates, which increases with the development of products, technologies for working with composites and a multiple reduction in price;

- development in the industry employees, the so-called softskills - non-specialized skills that make it possible to be successful in the profession: ability to work in a team, responsibility, emotional intelligence, critical thinking, time management. 
Thus, the strategic guidelines of the Bologna project had a positive impact on the development of higher education in Russia. In the practice of educational institutions for professional training of personnel for nuclear energy, which has an extensive structure of educational institutions, Bologna values show themselves in expanding cooperation with Chinese universities and educational centers on various aspects of professional education, the development of curricula, educational technologies, research projects.

\section{References}

1. Chinese citizens study in Russia: https://www.5top100.ru/news/104492 (2019)

2. V.I.Baidenko, Bologna Process: At the Threshold of the Third Decade//Higher Education in Russia. 27. 11. 136 (2018) (In Russ.) DOI: https://doi.org/10.31992/08693617-2018-27-11-136-148

3. E.S.Khovanskaya, A.V.Fakhrutdinova, N.V.Maklakova, University as a social phenome-non. Man in India. 97. 9. 101 (2017)

4. A.S.Chugunov, A.M.Ilsova, The Bologna process as a way to integrate higher education in Europe \& the Russian Federation, Kazan Bulletin of Young Scientists, 2. $125,(2019)$

5. Decree of the President of the Russian Federation "On the national development goals of the Russian Federation for the period up to 2030", dated July 21, 2020 No. 474, available at: https://base.garant.ru/74404210/ (accessed 15.12.2020).

6. News from $N R N U$ MEPhI: https://mephi.ru/content/news/1810/130851

7. News from NRNU MEPhI: https://mephi.ru/content/news/1387/126179

8. Atomic Expert, corporative journal, 1-2, (2020), URL: http://atomicexpert.com/

9. Xisong Dong Xiwei Liu, A Review of Engineering Education in China: History, Present and Future. Conference Paper (2017) ASEE International Forum: https://www.researchgate.net/publication/317012064

10. Tengteng Zhuang and Xiaoshu $\mathrm{Xu}$, New Engineering Education' in Chinese Higher Education: Prospects and challenges. Tuning Journal for Higher Education (TJHE), 6. 1 (2018) doi: http://dx.doi.org/10.18543/tjhe-6(1)-2018pp69-109

11. Abdul Sami Channa, Farrukh Raza Amin, Guangqing Liu \& Chang Chen,The Engineering Education in China, Compared to Pakistan, Europe, and the USA, in Prospects of One Belt, One Road. Higher Education Studies. 8.3 (2018) URL: https://doi.org/10.5539/hes.v8n3p15

12. Ana María Graffigna Vaggione, Lucía Mabel Ghilardi, and María Amelin Dávila Zarracán, Analysis of curriculum processes for the development of competencies in engineering education. Tuning Journal for Higher Education (TJHE). 7. 2. 25 (2020): http://dx.doi.org/10.18543/tjhe-7(2)-2020pp25-42

13. R. Vuorikari, Y. Punie, Gomez S. Carretero, G.Van den Brande. DigComp 2.0: The digital competence framework for citizens. Update phase 1: The conceptual reference model. Luxembourg: Luxembourg Publication Office. (2016) 